\title{
Structural aspects of the flame propagation theory
}

\author{
Alexander G. Merzhanov \\ USSR Academy of Sciences Institute of Structural \\ Macrokinetics, Chermogolovka, 142432 USSR
}

\begin{abstract}
The current state of the combustion theory and the prinoipal ways of its development, which is promoted by the flame struoture studies, are considered. Experimental and theoretical works on non- and steady-state one-dimensional flame structures and inhomogeneous ones, cellar and spin combustion among them, are reviewed for the last two decades. Great attention is paid to solid plames, in which the combination of chemical, physico-chemical, and thermodiffusional processes is quite an abundance.
\end{abstract}

\section{INTRODUCTION}

The theory of flame propagation is known to deal with the wave complex, whioh comprises the combustion and pre-flame zones and propagates through the reactants converting them into combustion products (Fig. 1). The front plane of the wave complex separates the pre-flame from combustion zones.

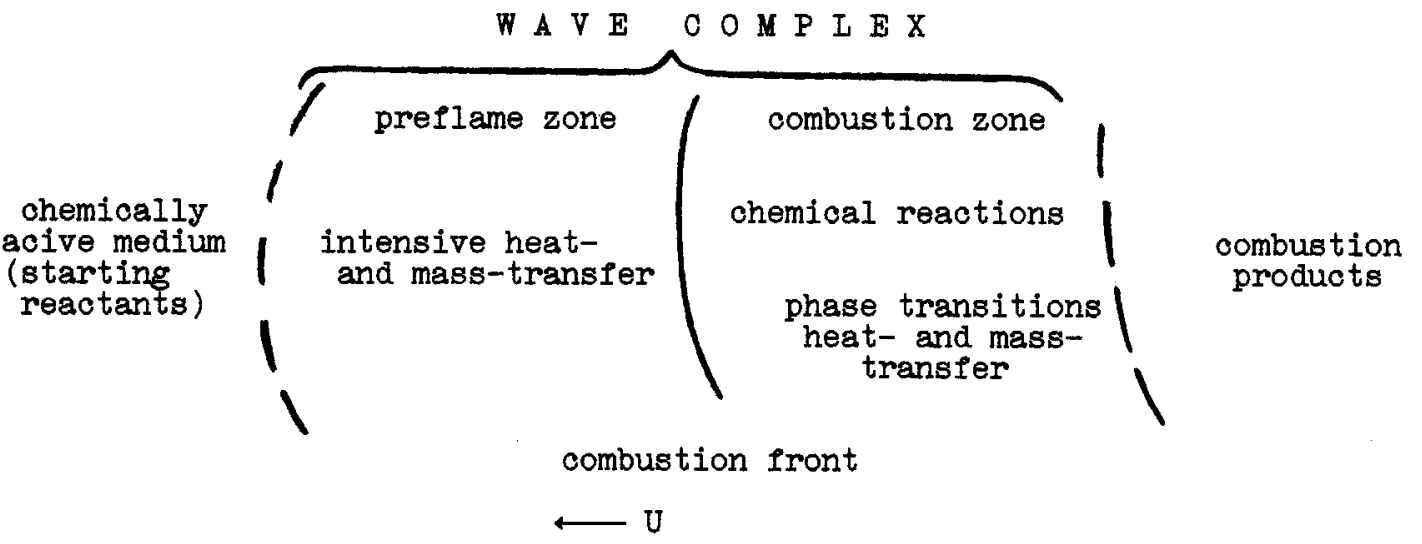

Flame propagation phenomena are normally studied along two general paths: the first is concemed with the laws of combustion front propagation:

$$
\mathrm{U}=\mathrm{U}(\mathrm{x}, \mathrm{y}, \mathrm{z}, \mathrm{t})
$$

where $U$ is the rate of the combustion front propagation, $x, y, z$ are space coordinates, $t$ is the time. These values are related by the equation of the front plane.

In this case, both instantaneous local and average $(\bar{u})$ velocities are determined for variable parameters characterizing the reactants involved and combustion conditions. The alternative approach focuses on th zone structure of the combustion wave and on the determination of the set of values that are critical for understanding the process: temperature (T), concentration of the reaotants and combustion products $\left(C_{i}\right)$, pressure ( $P$ ), displacement rates of the reaction medium (U) etc. Therefore, the flame structure charaoterization is usually assoolated with finding a oomplete or partial solution to the relationships: 


$$
\left.\begin{array}{l}
\frac{T}{C_{1}} \\
P \\
v
\end{array}\right\}=\varphi_{j}(x, y, z, t)
$$

Both problems, i.e. Iront propagation velocity and flame structure, are closely related and therefore they are often treated jointly in combustion mechanism studies. In general, complex process of flame propagation breaks down into various simpler modes. Of these, the most common is a one-dimensional combustion wave, which is steady-state within the coordinate system moving concurrently with the combustion front.

$$
\left.u=\text { const } \begin{array}{l}
\frac{T}{C} \\
P_{i} \\
v
\end{array}\right\}=\varphi_{j}(x) ; x=x+u t
$$

There are also non-steady-state waves, which either pertain to transition prooesses or develop when one-dimensional steady-state waves lose stability. In this case, spatially inhomogeneous regimes may arise, which are steady within the relevant coordinate system.

Pioneering results in flame propagation theory were first reported by Zeldovich and Frank-Kamenetskii in 1938 (ref.1). They considered the simplest case:

$$
\begin{aligned}
& U=U(x, y, z, t)=\text { const } \\
& T=T(x, y, z, t)=T(x) \\
& C_{\text {in }}=C_{\text {in }}(x, y, z, t)=C_{\text {in }}(x) \\
& C_{f}=C_{f}(x, y, z, t)=C_{f}(x) \\
& P=P(x, y, z, t)=\text { const } \\
& v=v(x, y, z, t)=0
\end{aligned}
$$

where $C_{\text {in }} C_{1}$ are concentrations of starting and final products, respeotively. Using reasonable additional assumptions (homophase process occurring in the gaseous mixture, ocourrence of the $n$-th order reaction, equal coefficients of thermal diffusivity and diffusion etc.), they were the first to calculate both flame propagation velooities and flame stmucture (including, naturally, the structure-velocity relation). The ZeldoviohFrank-Kamenetskii wave structure is schematically given in Fig. 2. The equations for the flame propagation velooity, $U$, and the highest combustion temperature, $\mathrm{T}$, take the form:

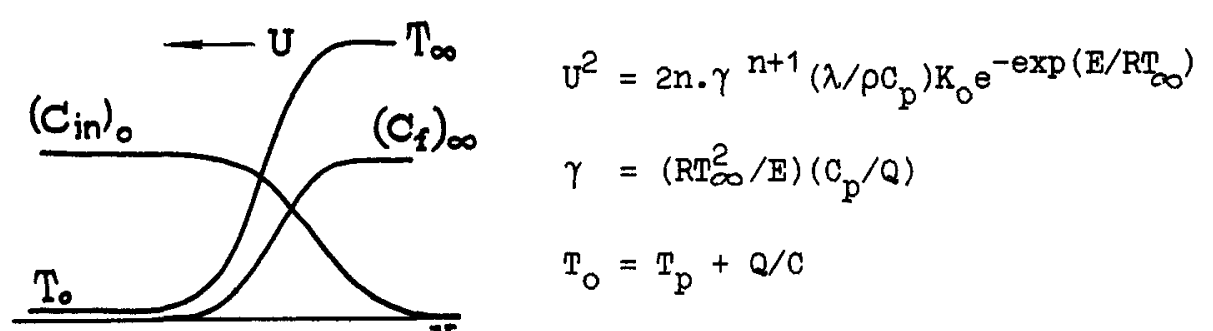

Fig. 2: The Zeldovich-Frank-Kamenetskii flame propgtion theory (the simplest case).

where $n$ is the order of the reaction, $K_{0}$ is the pre-exponential faotor, $F$ is the activation energy, $Q$ is the reaction thermal effect, and $\lambda, C_{p}$ and $\rho$ are the thermal condutivity coefficient, specific heat, and the starting mixture density, respectively, $T_{0}$ is the temperature of the starting mixture, $R$ is the gas constant.

According to Zeldovich and Frank-Kamenetskil the flame velocity relates to the highest combustion temperature (found from thermodynamic oalculations), and the extent of the combustion zone (in both $X$ and $T$ ) is much smaller than the pre-flame zone. These concepts formed the basis for numerous studies in the field of the flame propagation theory. 
1. Combustion of gases

\begin{tabular}{ll|l}
\hline gas & $\mathrm{U} \leftarrow$ & gas \\
\hline
\end{tabular}

Combustion chemistry Turbulence

3. Gas-suspension combustion

\begin{tabular}{c|l}
\hline gas - \\
suspension $U \leftarrow$ & $\begin{array}{l}\text { gas or gas- } \\
\text { suspension }\end{array}$ \\
\hline
\end{tabular}

Medium heterogeneity

Heat transfer mechanism
2. Combustion of gasifying condensed system

\begin{tabular}{l}
$\begin{array}{l}\text { condensed } \\
\text { substance }\end{array}-\mathrm{gas}$ \\
\hline $\begin{array}{c}\text { Gasification mechanism } \\
\text { Multi-stage heat release }\end{array}$
\end{tabular}

4. Filtration combustion

\begin{tabular}{l|ll}
\hline $\begin{array}{l}\text { porous } \\
\text { body }\end{array}$ & $\begin{array}{l}\text { porous } \\
\text { body }\end{array} \stackrel{\leftarrow \text { gas }}{\rightarrow}$ \\
\hline
\end{tabular}

Filtration processes

Thermal instability

5. Gasless combustion

\begin{tabular}{ll|l}
\hline condensed & $\mathrm{U} \leftarrow$ & $\begin{array}{l}\text { condensed } \\
\text { substance }\end{array}$ \\
\hline
\end{tabular}

Medium heterogeneity

Heat transfer mechanism

Thermal instability

Formation of product stmucture

Fig. 3: The best studied types of combustion systems.

of prime importance in flame propagation processes is the aggregative state of the original mixture and combustion products. Some of the best studied cases are presented in Fig. 3. The basic concepts of Zeldovich and FrankKamenetskii were lurther developed and extended in the studies devoted to the analysis of the processes specific for the combustion types under consideration (also presented in Fig. 3) (refs. 2-5).

The moderm theory of flame propagation constitutes a huge part of the general combustion soience. Therefore, any treatment of the problem on a less than monograph scale is bound to be severely limited. The present paper deals only with some of the stmuctural aspects of the flame propagation theory. These include:

- one-dimensional steady-state structures,

- one-dimensional non-steady-state stmuotures,

- non-one-dimensional structures.

It is believed, that the major breakthrough in the development of combustion theory can only be achieved via studies of the known and identification of new flame stmuctures. The data to be considered were obtained either from experimental flame studies (measuring the temperature and concentration fields) or by computer simulation (numerioal solution of the equations for conservation of energy momentum, substances with the non-linear sources, Plame structure calculations). The discussion is mainly based on the results obtained by the author and his olosest colleagues. Also presented will be results from the solid flame structure investigations, that are little known to a wide soientific community (ref. 6). The aim of the present paper is, by way of concrete examples, to demonstrate the importance of flame stmucture studies for a further and better understanding of the nature of combustion.

\section{STEADY-STATE ONE-DIMENSIONAL FLAME STRUCTURE}

These structures have received the most study due to their simplicity and common occurrence. Nuch useful information acoumulated in these studies has contributed to a further development of the Zeldovich and Frank-Kamenetskii concepts (ref. 1).

A basioally new concept of broad reaction zones was proposed by Khaikin, Aldushin, and the author in 1979 (ref. 7), based on the analysis of gasless combustion in mixture of metal and non-metal powders. It is found that strong inhibition of the reactants interaction due to the layer of solid final products, combined with a typical of heterogeneous systems semidispersity of the starting mixture which comprises coarse, hard-to-burm and easily buming fine particles, cause a marked broadening of the reaction zone. The concept of narrow and broad zones is schematically presented in Fig. 4. Narrow zones are described by the ratio $x_{r} / x_{T} \ll 1$, broad ones - by 



Fig. 4: Narrow and broad zones in the llame propagation theory.

the inverse ratio $x_{r} / x_{T} \gg 1\left(x_{r}\right.$ is the width of the chemical reaction zone, $x_{T}$ is the width of the superheated layer (pre-flame zone). In narrow zones, the combustion rate is related to the highest (thermodynamio) combustion temperature, $\mathrm{T}_{\infty}$, in broad zones it depends on some intermediate temperature, $T_{*}$, which should be calculated using additional considerations. To this end, the temperature profiles across the combustion waves in broad zones were measured by means of thermocouples. As an example Fig. 5 presents the wave profiles for the oombustion of the mixture $\mathrm{Ta}+2 \mathrm{~B}$ derived and calculated from Zenin's et al. data (ref.8). An anomalously wide reaction zone is present on the heat-release $Q \Phi=f(x)$ and conversion $\eta=\eta(x)$ ourve, as well as in the phase diagram q-T. Wide zones were also detected optically, by photographing the process using strong filters.

The concept of broad reaction zones representing a "non-Zeldovich" approach in the flame propagation theory has been applied to various processes of heterogeneous combustion.

The combustion wave stmuoture is closely related to the mechanisms of chemical reactions in flame, which yield intermediate products and involve spatially separated steps. Gases or completely gasified condensed systems are best suited to study the formation of chemical conversions in flames. This approach takes advantage by the direct measurements of the temperature as well as concentration profiles for the reactants and reaction products, and yields a complete picture of the chemical reactions occurring in flames.
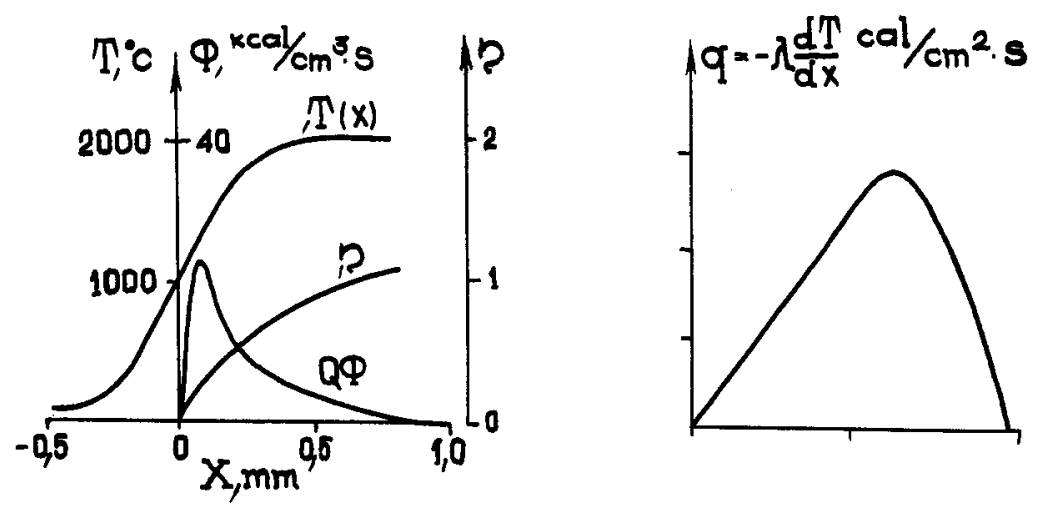

F1g. 5: Combustion of the $\mathrm{Ta}+2 \mathrm{~B}$ mixture. 


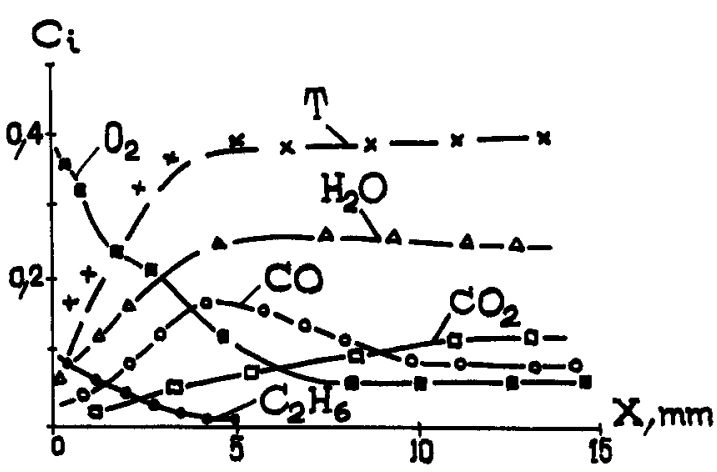

Fig. 6: Combustion of the $11.8 \% \mathrm{C}_{2} \mathrm{H}_{4}+41.5 \% \mathrm{O}_{2}+46.7 \% \mathrm{Ar}$ mixture.

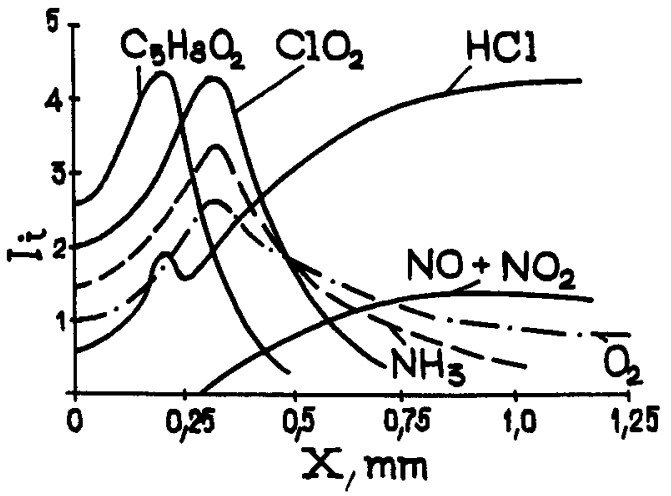

Fig. 7: Combustion of the ammonium perchlorite polymethylmetaryl mixture $(84 \%: 16 \%)$.

As an example Fig. 6 presents the chemistry of the combustion in the mixture $11.8 \% \mathrm{C}_{2} \mathrm{H}_{6}+4.5 \% \mathrm{O}_{2}+46.7 \% \mathrm{H}$, based on the data of (ref. 9). The profiles show that the starting materials $\mathrm{C}_{2} \mathrm{H}_{6}$ and $\mathrm{O}_{2}$ diminish, the concentrations of the final products $\mathrm{H}_{2} \mathrm{O}$ and $\mathrm{CO}_{2}$ increase, and that of intermediate product CO passes through a maximum. A similar flame structure for the condensed gasifying mixture ammonium perchlorate-polymethylmetacrylate (84:16\%) is depicted in Fig. 7 according to the data from (ref. 10). It is conspicuously richer in intermediate products.

All too often, various chemical stages show up in the $T(X)$ ourves as temperature stages. Fig. 8 presents the temperature profile of the combustion wave in the ballistite powder $\mathbf{N}$ (ref.11). The two apparent stages are identified as the endothermal decomposition of the powder and the gas-phase Co after-burning. In the gasless combustion (solid flame) studies, the measurements of the temperature profiles combined with additional experimentation, furnish a most efficient method for the study of chemical reaotion sucoessions in flames. Fig. 9 presents a two-stage profile for the

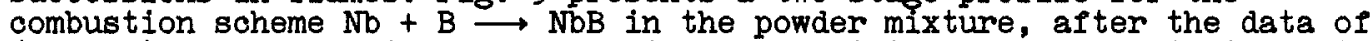
(ref. 8). The analysis of the profile and additional evidence indicate that a seemingly simple reaction of the monoboride formation from elements in solid flame involves the intermediate formation of niobium diboride. In contrast to gas flames, the study of solid flame struotures faces a methodically complex problem of measuring the species concentration profiles. So far, this problem has not been solved, blocking the study of the chemistry of gasless combustion waves. A new approach to investigation of the solid flame chemical stmucture, currently underway, employs rapid extinction of the combustion process (solid flame quenching) with subsequent layer-by-

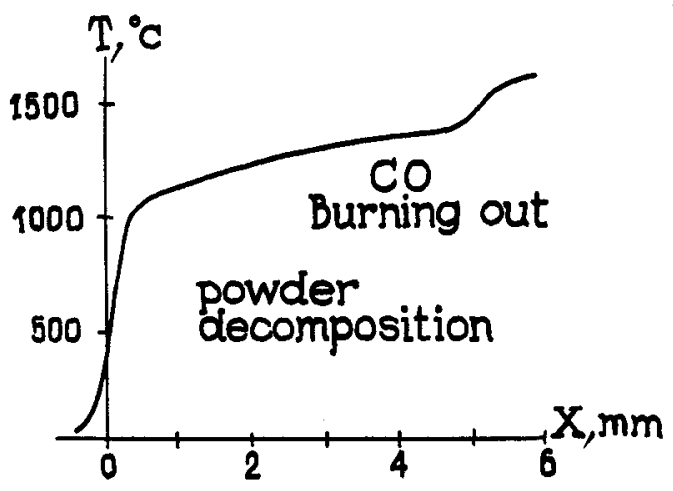

F1g. 8: Combustion of the gun powder "N"

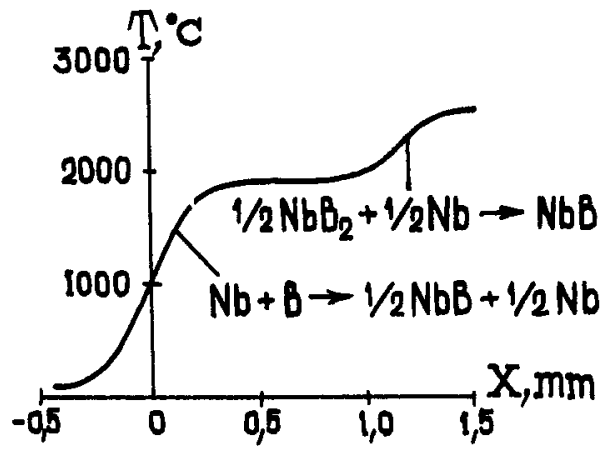

Fig. 9: Combustion of the $\mathrm{Nb}+\mathrm{B}$ mixture 


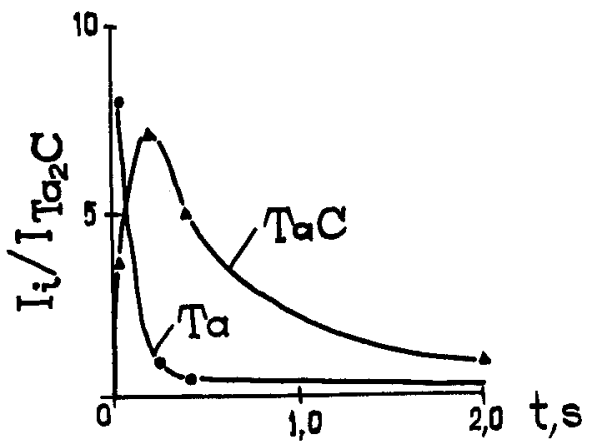

Fig. 10: The changes in the relative intensity of the $X-$ ray diffraction maximum along the $2 \mathrm{Ta}+\mathrm{C}$ quenohed sample. $\mathrm{I}_{\mathrm{Ta}_{2} \mathrm{C}}$ is the line intensity

layer analysis of the quenched product. This is illustrated in Fig. 10, which presents the concentration profile for the reaction:

$$
2 \mathrm{Ta}+\mathrm{C} \rightarrow \mathrm{Ta}_{2} \mathrm{C}
$$

in the combustion wave, obtained in this way (ref. 6). It is seen, that the formation of semicarbide passes via the formation of intermediate tantalum monocarbide (similarly to the borating reaction in Fig. 9). Theoretical aspects of the step-by-step combustion caused by chemical transformations were treated by Khaikin and colleagues (reis. 12,13).

The phase transitions (melting, evaporation, polymorphous transformations) ocourring in the reactants and products are found to determine the shape of temperature profiles due to the thermal effects from conversion and varying reactivities of the phases. In general, the role of phase transformations in flame structures was considered in (refs. 14-16). Schematic representation of the profile types is given in Fig. 11. The shape of a profile depends very strongly on the zone, in which phase transformation occurs. If the phase transition temperature lies in the pre-flame zone $\left(T_{0}<T_{p}\left\langle T_{*}\right)\right.$ only minor distortions in the profile shape are recorded (an inflection in the temperature derivative at the transition point). Phase transitions, which ocour simultaneously with the chemical reaction $\left(\mathrm{T}_{*}<\mathrm{T}_{p}<\mathrm{T}_{\infty}\right)$ gives rise to a temperature plateau $T_{p}$ (isothermal area) on the temperature profile. The occurrence of the area points to the heat balance, $i . e$. the released chemical heat is consumed completely by phase transition. Fig. 12 presents a seotion of the temperature profile recorded in the combustion of the Ti $+0.6 \mathrm{Si}$ mixture, using optioal-spectral methods (ref. 17). The profile contains a distinct isothermal area, whioh corresponds to the titanium melting point.

All chemical reactions and phase transitions show up on the combustion wave temperature profiles as numerous and varied thermal effects. Their

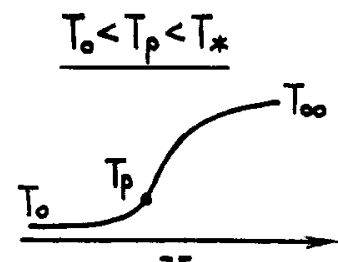

$\mathbf{x}$

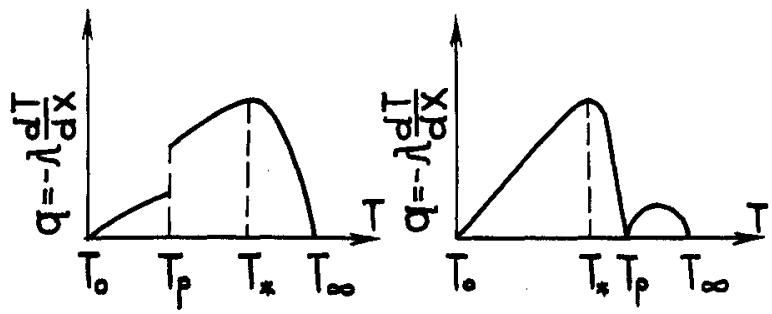

Fig. 11: Sohematic representation of the temperature profiles 


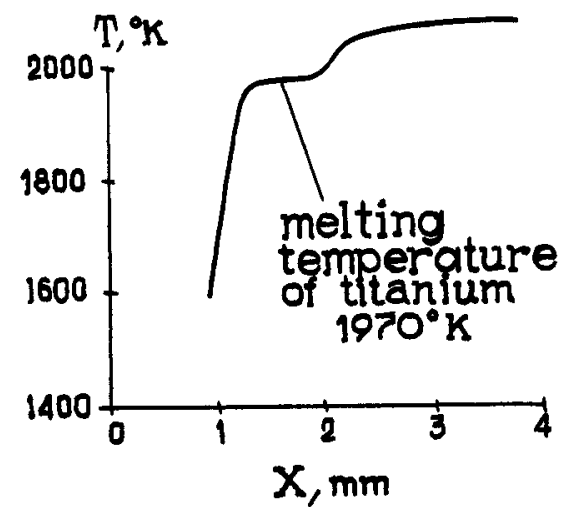

Fig. 12: Combustion of the Ti $+0.6 \mathrm{Si}$ mixture

identification presents an important problem in the physico-chemical studies on flame structure. Solid flames are particularly abundant in such effects. As an example, Fig. 13 shows the temperature profile of the combustion wave in the system 5Ti $+3 S i$, as derived from the data of Zenin and Nersesyan (ref. 18). Based on their additional studies, the authors performed a physico-chemical interpretation of the effects observed on the profile.

A mere statement of the relations between the flame struoture and chemical reaction mechanisms, phase transformations and macrokinetic manifestation of the heterogeneous systems indioates readily that the relationship between the flame propagation rate and flame structure, proposed by Zeldovich and Frank-Kamenetskil is only too simple and does not allow for the real properties of the flame stmucture, whioh involves zones with various processes or effects. However this scattered picture is amenable to generalization. Rumanov et al. (ref. 19) have proposed three major combustion modes, each having its own structural expression. The first one is a merging mode. All the processes ooourring in the flame form a single zone with a monotonically increasing temperature. The combustion rate is defined by the processes occurring in the vicinity of the highest temperature, $T$, in conformity with the Zeldovich and Frank-Kamenetskii theory. The second is the breaking-away regime. Its distinotive feature is the presence of a zero-derivative point, or isothermal area, on the temperature profile. It can be said, that the flame structure consists of two parts - a low-temperature one, with the processes determining the front propagation rate, and a high-temperature part, which exerts no influence on the wave propagation process. The control regime fumishes the third type of the combustion mode. It is characterized by inflections, which appear on the profile ourve with a non-zero derivative. On the whole, the combustion rate is determined by the high-temperature zone and displacement of the low-temperature zone with desired velocity is determined by the heat flux. Having analyzed the findings from the high-temperature zone of numerous theoretical and experimental studies on the combustion wave stmoture and its impact on the front velocity in various particular cases, the author

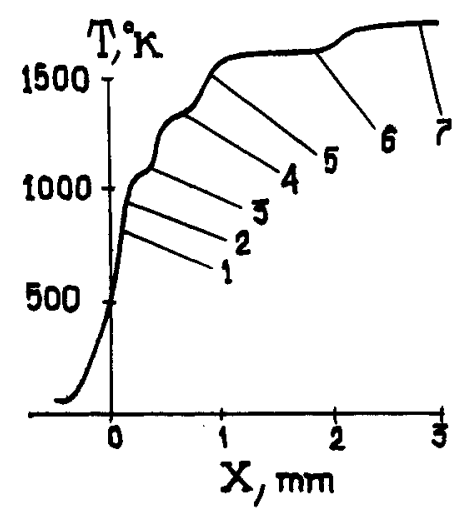

Fig. 13: Combustion of the 5Ti+3Si mixture (the grain size $<45 \mu \mathrm{m}$ )

$1-\mathrm{T}=880^{\circ} \mathrm{C}, \mathrm{Ti}_{\alpha} \rightarrow \mathrm{Ti}_{\beta}$;

$2-5 \mathrm{Ti}+3 \mathrm{Si} \longrightarrow \mathrm{Ti}_{5} \mathrm{Si}_{3}$ (solid phase reaction);

$3-\mathrm{T}=1170^{\circ} \mathrm{C}, \mathrm{Ti}_{5} \mathrm{Si}_{3}+\mathrm{Ti} \rightleftarrows \mathrm{Ti}_{3} \mathrm{Si}$ (peritectic reaction);

$4-\mathrm{T}=1350^{\circ} \mathrm{C}, \mathrm{Ti}_{5} \mathrm{Si}+\mathrm{Ti}$ (eutectic formation);

5 - TiSi 2 , Tisi formation;

$6-\mathrm{T}=1530^{\circ} \mathrm{C}, \mathrm{TiSi} \mathrm{i}_{2}$ melting;

7 - mixture homogenization and $\mathrm{Ti}_{3} \mathrm{Si}_{3}, \mathrm{TISi}_{2}, \mathrm{TiSi}$ eto. formation 
proposed a generalized formula for the front propagation velocity in the systems with complex wave structure (ref. 15). The formula takes the form:

$$
\mathrm{U}^{2}=\mathrm{A}\left(\mathrm{T}_{*}, \eta_{*}\right) \exp \left(-\mathrm{E} / \mathrm{RT}_{*}\right)
$$

where $\mathrm{T}_{*}$ and $\eta_{*}$ are certain intermediate temperatures and conversion values, that should be determined additionally, $E$ is the effeotive aotivation energy at the major step, $A\left(\mathbb{T}_{*}, \eta_{*}\right)$ is the weak power function.

$T_{*}$ and $\eta_{*}$ can be determined from the following conditions:

a) narrow zones, the Zeldovich and Frank-Kamenetskii formula

$$
\eta_{*}=1, T_{*}=T=T_{0}+\left(Q / C_{p}\right)
$$

b) broad zones

$$
\begin{aligned}
& \Phi=\Phi(T, \eta) \\
& (Q / C) \Phi_{广}^{\prime}\left(T_{*}, \eta_{*}\right)+\Phi^{\prime}\left(T_{*}, \eta_{*}\right)=0 \\
& T_{*}=T_{0}+(Q / C) \eta_{*}
\end{aligned}
$$

c) ohemioal reaction steps, the break-away mode

$$
\eta_{*}=1, T_{*}=T_{0}+Q_{I} / C_{p}
$$

$Q_{I}$ is the thermal effect of the low-temperature step

d) phase transition, the isothermal plateau

$$
\eta_{*}=\left(C_{p} / Q\right)\left(T_{p}-T_{0}\right), \quad T_{*}=T_{p}
$$

The relation between the combustion rate and flame structure is one of the major problems in steady-state combustion theory. This area is being actively investigated.

Many unexpeoted and important results have been obtained from studies on the filtration combustion regimes in systems porous body-gas (refs. 20-22).
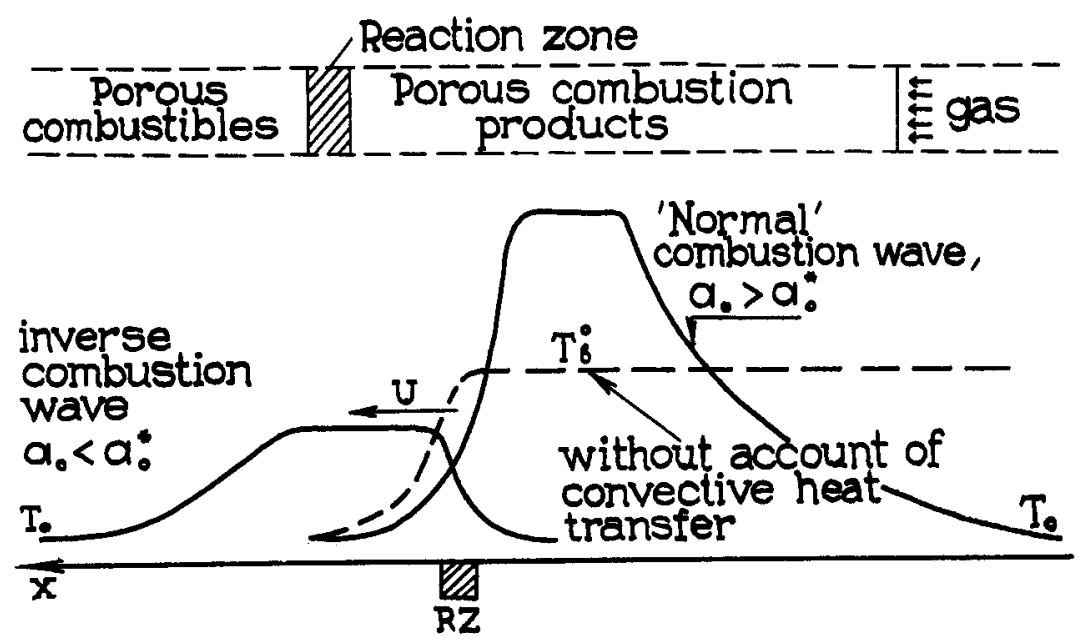

Pig. 14: Direct and inverse combustion waves at the gas filtration through the product

Let us consider only one example. Aldushin and Seplyarskil (rels. 21, 22) studied a theoretical model of combustion with forced concurrent filtra-tion (the reactant gas was blown through the porous sample). The convective heat exchange between gas and porous body was taken into acoount. Two extremely interesting flame struotures and, respeotively, two combustion regimes were 
discovered. Fig. 14 presents sohematioally the steps of the process and the temperature profiles for these two oases. In one regime, flame propagates in the normal fashion, though the combustion temperature is anomalously high (superadiabatio). In this case, the filtrating gas takes heat away from the combustion products and carries it into the combustion zone, thereby inoreasing its temperature. In the second regime, an abnormally broad heated layer is built up (due to conveotive heat exohange) and the combustion product undergoes rast quenching. Here, heat is lost from the combustion products and also erom the reaction zone with the result that combustion in this regime proceeds at temperatures below the adiabatio values. The authors named the regime "an inverse combustion wave".

\section{NON-STEADY ONE DIMENSIONAL FLAME STRUCTURE}

Non-steady-state stmotures in flame propagation theory have been studied to a lesser extent. This seotion will deal with two types of unsteady structures illustrated by several examples.

Ignition processes represent the simplest case of the unsteady structure formation. Heat produced during ignition from an external source, gives rise to a wide pre-heated layer, which then burns away with the formation of $a$ wave with steady-state structure. The formation step is charaoterized by a strong dependence of the wave structure properties on time: $T=T(x, t) ; \eta=$ $\eta(x, t) ; U=U(t)$.

Figures 15 and 16 present typical ignition-produoed unsteady llame structures after data of (ref. 23). The analysis shows that structure types and $U(t)$ dependenoe are defined by the ignition regime or to be more exact, by the ignition-to-combustion temperature ratio $\mathrm{T}_{\text {ign }} / \mathrm{T}_{\infty}$ At $\mathrm{T}_{\text {ign }}<\mathrm{T}_{\infty}$, there occurs the induction ignition mode, whioh develops a wide pre-heated layer characterized by the ratio $U(t)>U_{s t} \cdot A t T_{i g n}>T_{m}$, the combustion of the mixture occurs during the unsteady step, and a heated layer is practically non-existent during ignition. Interesting results have been obtained by Strunina and colleagues in their study (refs. 24,25) on flame structure and gasless combustion regimes using theoretical and experimental approaches, these authors investigated alterations occurring in steady-state combustion regimes in composite systems on transition from one mixture to another.

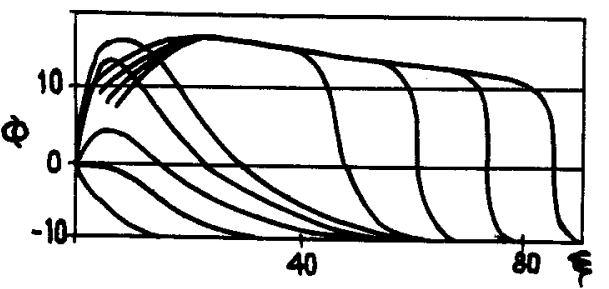

Fig. 15: Ignition under the induction regime.

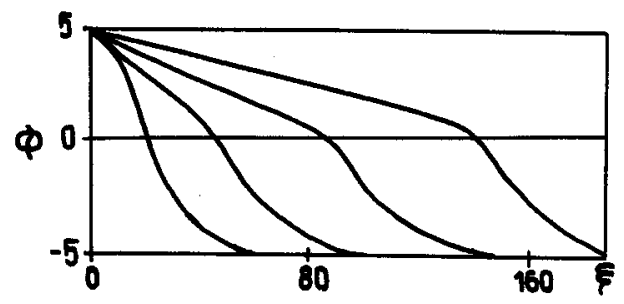

Fig. 16: Ignition in the burning-out regime.

The second type of unsteady structures develops, when steady-state wave loses its stability. In this case, the process is known to proceed at a variable instantaneous rate and either ends up in extinction or promotes the onset of a non-steady-state (periodic) regime. A typical example of unsteady but stationary regime is furnished by oscillatory combus tion. It was first discovered in gasless systems as a result of a numerical computer analysis of the mathematical model (ref. 26). Fig. 17 presents the temperature profiles at different moments of time (at equal intervals) for concrete parameter values. Strict periodicity is apparent. It appears that the process consists of alternating flashes and depressions. During depressions, owing to heat release, hot condensed products of gasless combustion form a pre-heated layer, which bums out quickly during a flash, and then reappears repeatedly: Osoillatory combustion has been effected and studied experimentally by Filonenko, Borovinskaya, Shkiro, Strunina in collaboration with the author (refs. 27-29). Fig. 18 is a typical photoregistogram of osoillatory combustion (photographing on a moving film), which is a plot of the front coordinate in a vertioaliy positioned sample va. time. Osolliations show up as small notches on the photoregistogram. It is interesting, that the sample 


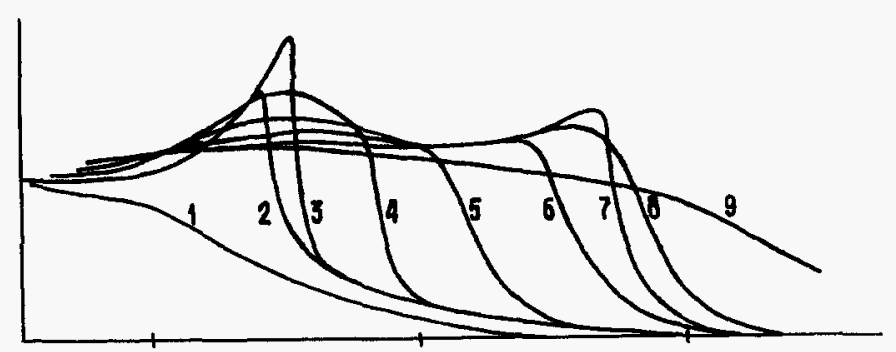

Fig. 17: Temperature profiles at different periods of autooscillatory combustion.

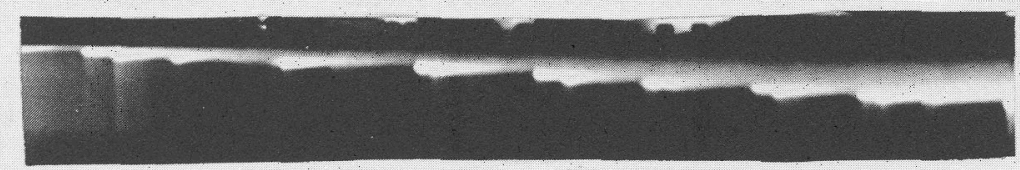

Fig. 18: Photoregistogram of autooscillatory combustion

burned in the oscillatory combustion consists of as many waffers as there have been oscillations (Fig. 19). It is clearly seen, that the waffers are flat, which confirms the existence of a planar (one-dimensional) combustion front under these regimes. A somewhat unique picture is presented in Fig. 20 (ref. 30). It is a transverse microsection of a silicon cylindrical sample burnt in gaseous nitrogen. The sample was ignited over the entire lateral surface and the combustion front propagated radially towards the axis. In the steady- state combustion regime, the burned sample was homogeneous silicon nitride, $\mathrm{Si}_{3} \mathrm{~N}_{4}$. Oscillatory combustion yielded a product, that consisted of altermateing layers of silicon nitride and unburnt silicon. The layer of unburnt silicon developed as a result of silicon melting owing to heat transfer from the adjacent burnt layer and a sharp decrease in the area of surface reacting with nitrogen during depression. Shkiro and Nersesyan ( $r$ ef. 28) carried out an experimental investigation of pulsation (oscillation) struotures at different stand-off distance from the loss-ofstability limit by means of decreasing $T_{\text {cm. }}$. It was found that the pulsation structure becomes more and more complex as the distance from the limit is increased.

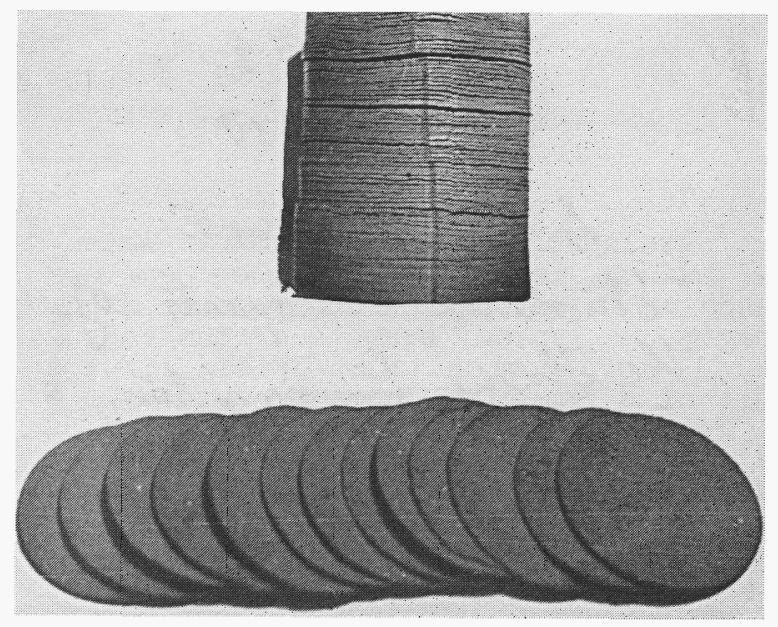

Fig. 19: The sample burnt out in auotooscillatory combustion

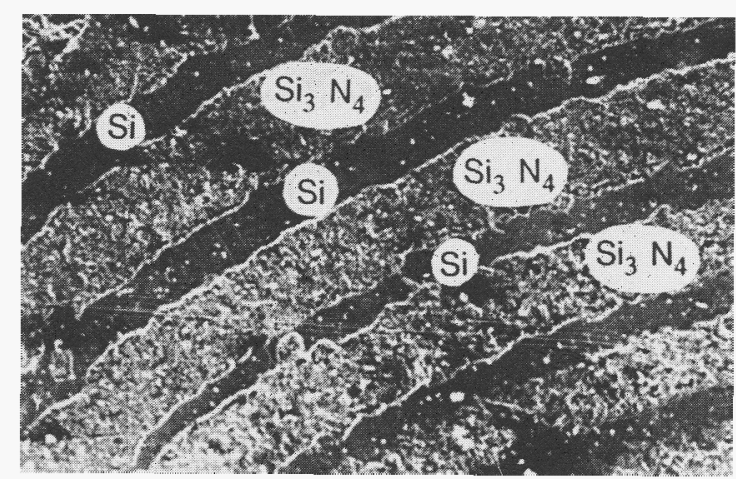

Fig. 20: Microstructure of $\mathrm{Si}_{3} \mathrm{~N}_{4}-\mathrm{Si}$ sample burnt out under the autoosoillatory regime (x300). 
A series of numerical calculations performed by Matkowsky (ref. 31) revealed further doubling of the oscillatory periods as well as other effects, which make the picture yet more complex. One of the major objectives pursued by studies of unsteady one-dimensional structures is aimed at determining the relationship between the mean combustion rate and the characteristics of an unsteady but stationary regime.

\section{INHOMOGENEOUS STRUCTURES}

Combustion which is accompanied by heat losses is the simplest and trivial process with the non-one-dimensional structure. Heat losses build up temperature distribution across the section of the burming sample, with the resulting curvature in the front line. A typical example is illustrated in Fig. 21 (ref. 32). It shows the front lines during combustion of a gasless cylindrical sample, in which heat losses occur through a side surface. The solution was obtained by numerical integration of corresponding two-dimensional equations.

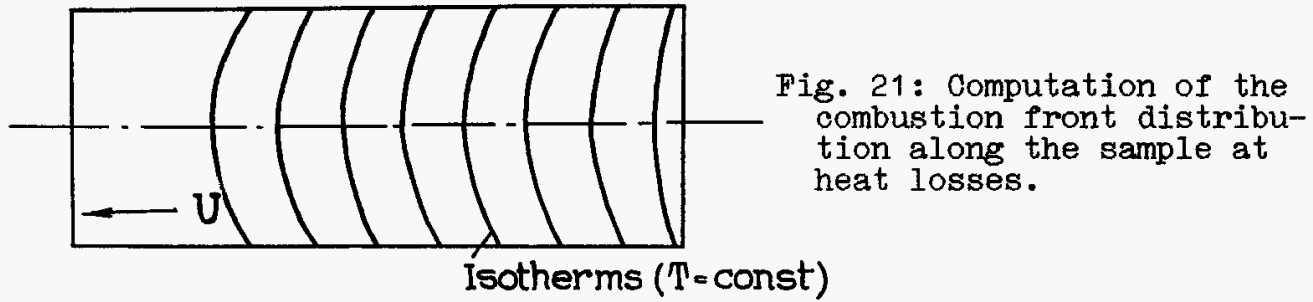

Nore complex processes cause distortion of the front during the filtration combustion of porous metal samples, inactive gas medium le.g., nitrogen (ref. 33)), when gas filtrates spontaneously through the side surface. Two limiting regimes are normally recognized in this case - a layer-by-layer surface combustion, which varies with the ratio of filtration to chemical reaction characteristic times, and intermediate regimes. Fig. 22 presents a photograph of a macrosection of tantalum sample burnt in nitrogen under certain parameters (ref. 34). The sample was quenched in liquid nitrogen at a certain time. The outer dark layer is formed of tantalum nitride (combustion product), the inner light one is the unreacted starting tantalum (which is also a nitrogen solid solution in tantalum). The boundary separating the dark from the light products represents a heavily curved combustion front (the combustion proceeded from left to right), and in this case, it shows that the process approximates surface combustion.

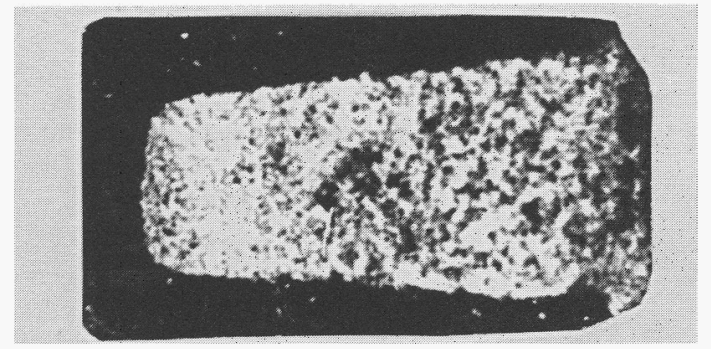

Fig. 22: Macrostructure of the titanium sample after combustion in nitrogen.

A mathematical modeling of such regimes of filtration combustion was performed by Shkadinskii and his colleagues (ref. 35). Fig. 23 shows the position of the front lines at different moments of time under certain parameters of the problem. It is seen that within the sample, the front is virtually motionless, its displacement being chiefly confined to the surface (surface combustion).

When the steady combustion regime with a planar front loses stability, there can develop not only unsteady one-dimensional regimes such as autooscillatory combustion, but also regimes (structures) characterized by considerable spatial inhomogeneity. A classic example of such stmuotures is cellar flame, long known from experimental studies (ref. 36). In this regime, the planar front breaks down into cells, which propagate along the combustion wave at a definite velocity. Some researchers maintain that 


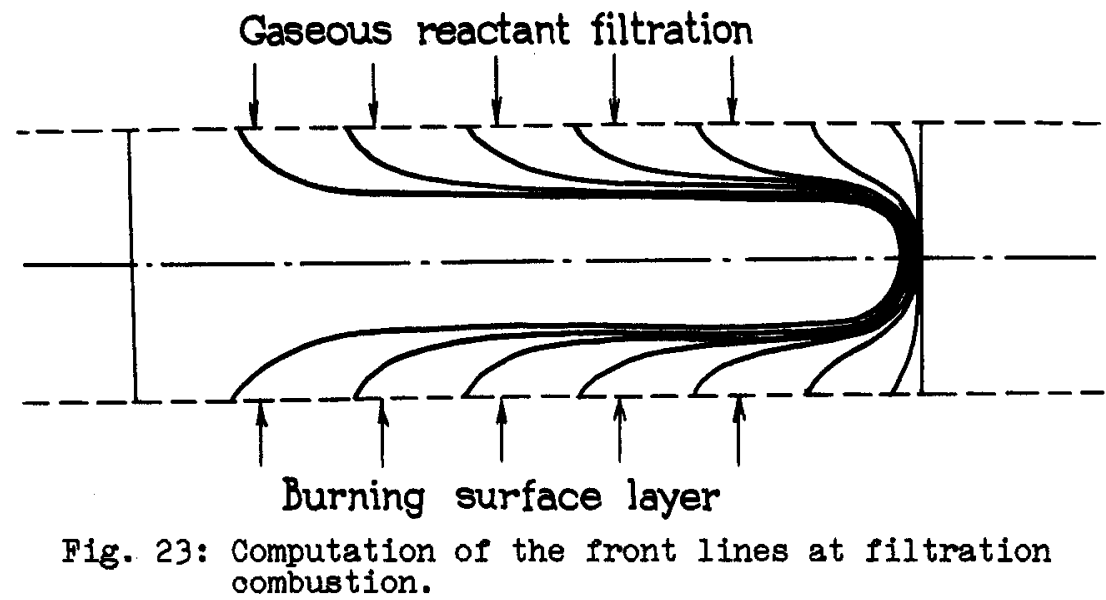

cellar flames are related to a loss of stability as a result of conveotion (ref. 37). Aldushin and colleagues (ref. 38) have found that oellar flames are formed by the diffusion-thermal mechanism. The problem reduoed to the solution of an ordinary two-dimensional non-di-mensional set of combustion equations:

$$
\begin{aligned}
& d \theta / d t=d^{2} \theta / d \zeta^{2}+\left(1 / d^{2}\right)\left(d^{2} \theta / d r^{2}\right)+(1-\eta) \exp [\theta /(1+\beta \theta)] \\
& d \eta / d t=I\left[d^{2} \eta / d \zeta^{2}+\left(1 / d^{2}\right)\left(d^{2} \eta / d r^{2}\right)\right]+\gamma(1-\eta) \exp (\theta /(1+\beta \theta)
\end{aligned}
$$

where $\theta$ is the temperature, $\eta$ is the concentration, $r$ is a longitudinal coordinate, $t$ is the time, $I$ is the Lewis number, $d$ is a nondimensional diameter, $\beta$ and $\gamma$ are the parameters of the combustion theory.

Numerical computer calculations showed that under oertain parameters the planar front exhibited ourvatures (kinks), which can be interpreted as cells. Fig. 24 presents a typical computational scheme of cellar flame. Note that the kinks move in the same direotion as the entire combustion wave.

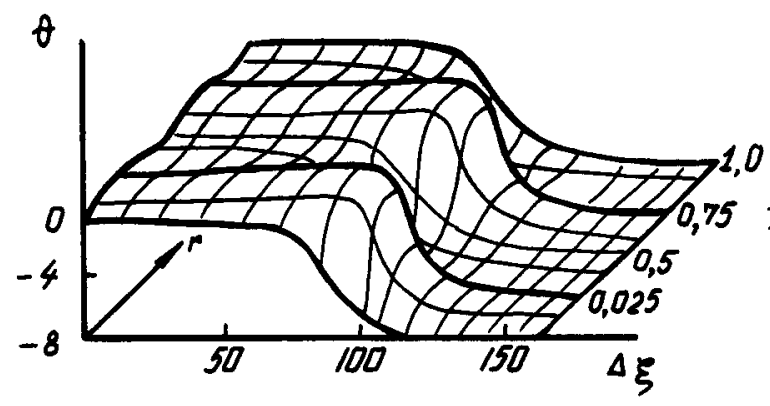

Fig. 24: Computational two-dimensional modelling of cellar combustion.

In 1973 the author in collaboration with his colleagues Filonenko and Borovinskaya discovered a new type of spatial inhomogeneity, which was named "spinning combustion" (ref. 39). Fig. 25 shows the first oinegram of such combustion (the system hafnium-nitrogen). During spinning combustion, the reaction does not reside in the planar layer as observed in wave propagation, but rather it is confined to a hot spot (spots), which moves in a helloal fashion along the surface of the sample. In other words, the spot moves transversely to the combustion wave, in contrast to a lengthwise displacement characteristic of cellar flames. Spinning combustion has aroused considerable interest. At first it was thought to be related to the instability of the surface regime of filtration combustion. Later on, however, spin waves were also observed in gasless (mixed) systems not subject to surface combustion. The most convincing proof was obtained by Shkadinskii et al. (ref, 40), who caloulated spin stmuotures on a computer by solving a two-dimensional set of equations for gasless combustion. 




Fig. 25: Cinegram of hafnium spin combustion in nitrogen:

Figure 26 is a calculated two-dimensional temperature field at a given time. Here $\theta$ is the temperature, $\zeta$ is the longitudinal coordinate, $\varphi$ is the tangential coordinate. Against the baokground of the essentially one-dimensional field, there is a hot spot (kink), which moves as noted above transversely to the wave propagation direction. Spinning combustion, being an unusual regime with spatially-inhomogeneous structure, was particularly attractive to mathematician-physicists who gave it considerable treatment and reliable mathematical substantiation (ref. 40).

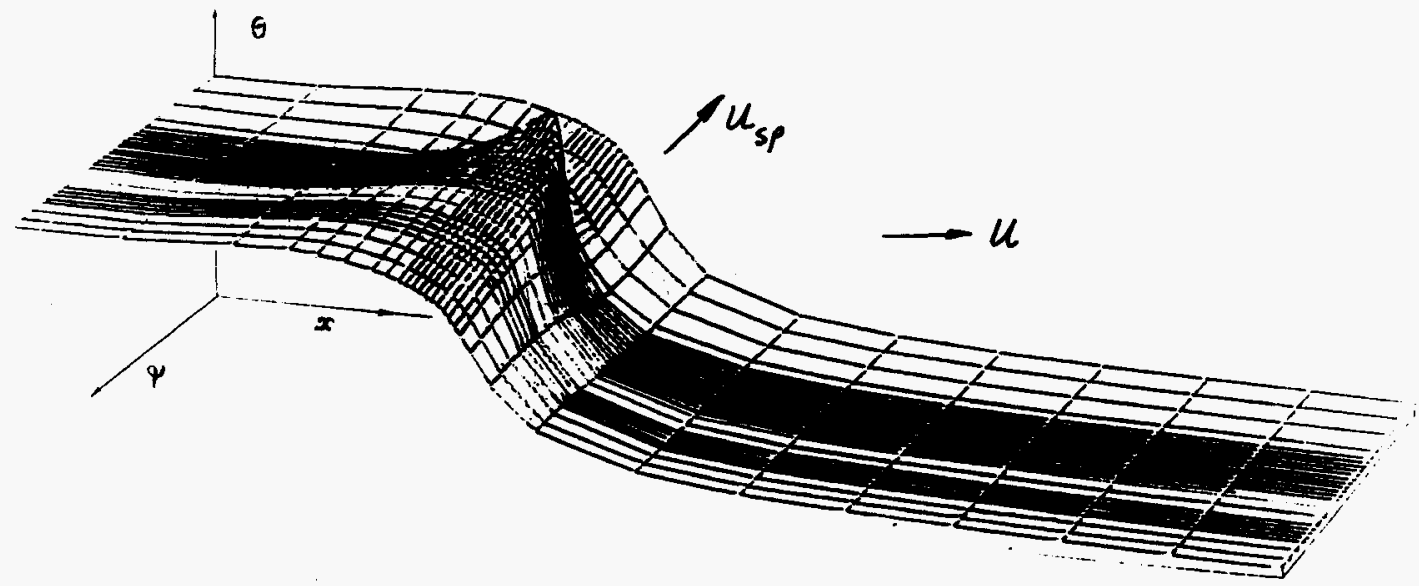

Fig. 26: Computational modelling of spin combustion.

It should be noted, that in early investigations on gasless and filtration combustion modes, which were developed as a related problem of self-propagating high-temperature synthesis (SHS), both autoosoillatory and spinning combustions were treated as entirely independent phenomena, with little (if any) relation to one another. However, further studies showed (refs. 42 , 43) that these phenomena are of common nature. Both autoosoillation and spin develop, when the steady-state planar front of the solid 1lame propagation loses its stability due to the conflicting existence of a heated layer and the reaction zone. Since the combustion rate depends very strongly on temperature, the heated layer formed by means of heat transfer from the reaction zone. Under the steady-state regime, the coexistence of the layers is stable to minor perturbations. A loss of stability triggers combustion of the heated layer. In this case, lack of stability (resistance) to longitudinal perturbations promotes the lengthwise (one-dimensional) combustion of the heated layer. Again, the mean descent super-heated condensed products in the solid flame develop a heated layer in the green mixture, which burns down in its turn. As a result, autooscillatory combustion develops, which proceeds as alternating liashes and depressions.

Loss of resistance to transverse perturbations gives rise to a hot-spot localization of the reaction and the spot thus formed begins to move along the heated layer. Under appropriate conditions, the process undergoes ordering and the spot then moves in a circular fashion. Insofar, as the heated layer reappears repeatedly (general wave propagation), the spot 
moves steadily and decsribes a helical path. This is a spinning oombustion mode. Consequently, both oscillatory combustion characterized by unsteady state and planar front, and the steady-state spinning oombustion, which is recognized a moving dissipative structure with a noted spatial inhomogeneity, are in effect but varieties of the modes, which are formed as a result of progressing instability of the steady-state combustion. It appears particularly attraotive to try to determine the boundary limits of varlous regimes in unstable combustion. This challenging problem has not yet been solved for solid flame.

\section{CONCLUSION}

We have discussed only some of the aspects of the flame propagation theory. It was shown what interesting and complex flame structures develop during combustion and how versatile and promising is the combustion picture for further studies. Solid flames, in which starting materials and combustion products are in solid state, have received the least study so far, but deserve special attention. These flames exhibit particularly rich interplay of various chemical, physico-chemical and diffusion-thermal processes.

of course, not all the problems bearing on the subject of the present talk, have been considered. We could not even touch on such issues as, for example, application of the temperature and concentration profiles measured across the plames in the studies on the mechanism and kinetics of chemical reactions, or the reactions between the flame structure and the chemical synthesis occurring in combustion waves, al though there has been acoumulated abundant material on these topios.

The author did not aim to propose a well balanced structural theory of flame propagation. Such a talk would be inconceivable within the scope of this report. Therefore, the discussion was restricted to certain ideas and examples, not neoessarily closely related to one another.

Flame structure is the problem that in spite of its rather long history is now going through rebirth. The advent of new electronic equipment, vastly enriched experimental techniques (refined, ingenuous etc.) ensures the inflow of reliable precise information of flame struoture. Moderm supercomputers have opened new possibilities in modeling complex stmotures and processes, in the development and enrichment of our concepts on the nature of combustion.

Identification and olose study of additional structures (non-one-dimensional, non-steady-state) of the mechanisms and laws controlling the randomness of plame, with increasing distance from the loss-of-stability limit, an understanding of relationships between the combustion rate (instantaneous and integral) and structures found in spatially inhomogeneous conditions all these lines are believed to be of immerse interest for further investigations.

\section{REFERENCES}

1. Ya.B. Zeldovich and D.A. Frank-Kamenetskii, Dokl. Akad. Nauk SSSR 19, 693-698 (1938).

2. A.F. Belyaev, Zh. Fiz. Khimil 12, 93 (1938).

3. O.M. Todes, A.D. Goltsinker, and Ya.G. Gorbulsky, Dokl. Akad. Nauk SSSR 205, 1083-1086 (1972).

4. A.P. Aldushin, A.G. Merzhanov, and B.I. Khaikin, Dokl. Akad. Nauk SSSR $215,612-615(1974)$.

5. A.G. Merzhanov, Arch. Proces. Spalan. 5, 17-39 (1974).

6. A.G. Merzhanov, A.S. Rogachev, A.S. Mukasyan, and B. Musid, Inzh.-Fiz. Zh. (1990) (in press).

7. A.P. Aldushin, A.G. Merzhanov, and B.I. Khaikin, Dokl. Akad. Nauk SSSR 204, 1139-1142 (1972).

8. A.A. Zenin, A.G. Merzganov, and G.A. Nersisyan, Dokl. Akad. Nauk SSSR $250,880-884(1980)$.

9. R.J. Hennesy, C. Robinson, and D.P. Smith, 21-th Symp. Combus. (1986), p. 761 .

10. O.P. Korobeinikov, A.A. Zenin, Yu.V. Tereshohenko, and V.M. Puchkov, Fiz. Gor. Vzryva 335-342 (1977).

11. A.A. Zenin, Fiz. Gor. Vzryva 68 (1966). 
12. B.I. Khaikon, A.K. Filonenko, S.I. Khudyaev, and T.M. Martenyanova, Fiz. Gor. Vervya 235-240 (1973).

13. B.I.Khaikin and A.G. Merzhanov, Progr. Ener. Combus. Soi. (1988).

14. A.P. Aldushin and A.G. Merzhanov, Dokl. Akad. Nauk SSSR 236, 1133-1136 (1977).

15. A.G. Merzhanov, Dokl. Akad. Nauk SSSR 233, 1130-1133.

16. A.G. Merzhanov, Phys. Chemistry. Modern Problems (Russ.), Ed. Ya.M. Kolotyrkin, pp. 5-45. Khimiya, Noscow (1983).

17. T.S. Azatyan, V.K. Maltsev, A.G. Merzhanov, and V.A. Seleznev, Fiz. Gor. Vzryva 43-49 (1979).

18. A.A. Zenin, G.A. Nersisyan, and A.G. Merzhanov, Chem. Phys. of Combus. Expl., Combus. of Condensed and Heterogen. Systems, pp. 63-67, ChermogoTovka (1980).

19. A.G. Merzhanov, E.N. Rumanov, and B.I. Khaikin, Zh. Prikl. Mekhaniki i Tekhn. Fiziki 99-105 (1972).

20. A.P. Aldushin, A.G. Merzhanov, and B.I. Khaikin, Dokl. Akad. Nauk SSSR $215,612-615(1974)$.

21. A.P. Aldushin, A.G. Merzhanov, B.S. Seplyarskii, Fiz. Gor. Vzryva 323$332(1976)$.

22. A.P. Aldushin and B.S. Seplyarskii, Dokl. Akad. Nauk SSSR 241,72-73 (1978).

23. A.G. Merzhanov, B.I. Khaikin, and K.G. Shkadinsky, PMTF 42-48 (1969).

24. A.G. Strunina, V.I. Ermakov, and V.V. Barzykin, Piz. Gor. Varyva 42-50 (1978).

25. A.G. Stmunina, V.N. Ermakov, and E.A. Averson, Fiz. Gor. Vzryva 77-84 (1979).

26. K.G. Shkadinsky, B.I. Khaikin, and A.G. Merzhanov, Fiz. Gor. Vzryva $19-28(1971)$.

27. Filonenko A.K., Combustion Processes in Chem. Teohnology and Metallurgy (Russ.) , pp. 258-274, Chermogolovka (1975).

28. V.M. Shkiro, I.P. Borovinskaya, and G.A. Nersisyan, Fiz. Gor. Vzryva $58-64(1978)$.

29. A.G. Stmunina and A.V. Dvoryankin, Dokl. Akad. Nauk SSSR 260, 1185-1188 (1981).

30. A.S. Mukasyan, A.G. Merzhanov, V.M. Martynenko, I.P. Borovinskaya, and M. Yu. Blinov, Fiz. Gor. Veryva 43-49 (1986).

31. A. Bayless and B.J. Matkowsky, J. Comput. Phys. 22, 737-744 (1987).

32. A.N. Firsov and K.G. Shkadunsky, Fiz. Gor. Vzryva 46-62 (1987).

33. A.G. Merzhanov, I.P. Borovinskaya, and Yu.E. Volodin, Dokl. Akad. Nauk SSSR 206, 905-908 (1972).

34. I.P. Borovinskaya, A.G. Merzhanov, A.N. Pityulin, and V.Sh. Shekhtman, Combus. Processes Chem. Technol. Metallurgy, pp. 113-118, Chermogolovka (1975).

35. T.P. Ivleva and K.G. Shkadinsky, Kinetics and Mechanism of Physicochemical Processes, pp. 74-75, Chermogolovka (1981).

36. G.H. Markstein, J. Aeronaut. Soi. 18, 199-220 (1951).

37. Non-Steady-State Flame Propagation, Ed. G.H. Narkstein (Russ. transl., -430 p., Mir, Noscow, 1968).

38. A.P. Aldushin, S.G. Kasparyan, and K.G. Shkadinsky, Dokl. Akad. Nauk SSSR 247, 1112-1115 (1979).

39. A.G. Merzhanov, A.K. Filonenko, and I.P. Borovinskaya, DokI. Akad. Nauk SSSR 208, 892-894 (1973).

40. K.G. Shkadinsky, T.P. Ivleva, and A.R. Merzhanov, Fiz. Gor. Vzryva 3-10 (1980).

41. V.A. Volpert, A.I. Volpert, and A.G. Merzhanov, Dokl. Akad. Nauk SSSR 262, 642-645 (1982).

42. V.A. Volpert, A.I. Volpert, and A.G. Merzhanov, Dokl. Akad. Nauk SSSR $263,918-921(1982)$

43. M.R. Booty, St.B. Margolis, and B.J. Matkowsky, SIAM, J. AppI. Math. $46,801-843(1986)$.

44. A.G. Merzhanov and E.N. Rumanov, Usp. Fiz. Nauk 151, 553-590 (1987). 